\title{
Iatrogenic Paralysis of External Popliteal Sciatic After OTV by Internal Addition
}

\author{
Youness Dahmani ${ }^{1 *}$, Ayoub Mjidila ${ }^{2}$, Mohammed Zaaf ${ }^{2}$, Tarik Hammamouch ${ }^{2}$, Georges Saad ${ }^{2}$, Adam Laribi $^{2}$
}

${ }^{1}$ Traumatology-Orthopedics Department, South-Essonne Hospital Center, Etampes
${ }^{2}$ Centre Hospitalier Sud Essonne Dourdan-Etampes - Siège: 26 avenue Charles de Gaulle - 91150 Etampes

DOI: $\underline{10.36347 / \mathrm{sasjs} .2021 . v 07 \mathrm{i} 01.008}$

| Received: 10.01.2021 | Accepted: 21.01.2021 | Published: 27.01.2021

*Corresponding author: Youness Dahmani

\section{Abstract}

The tibial valgus osteotomy by internal addition still holds an important place in the surgical arsenal against gonarthrosis, compared to the different valgus techniques and prosthetic surgery. Iatrogenic paralysis of the external popliteal sciatic nerve is a complication that must be taken into consideration in the aftermath of internal opening valgus osteotomy. This a 49 years old woman, with no notable pathological antecedent, admitted in our training for the management of right gonalgia evolving since 3 years, The evolution was marked by a paralysis made of steppage with an equinus foot without anesthesia of the territory of the anterior tibial nerve.

Keywords: Valgus, osteotomy, internal addition, external popliteal sciatic, paralysis.

Copyright $\odot 2021$ The Author(s): This is an open-access article distributed under the terms of the Creative Commons Attribution 4.0 International License (CC BY-NC 4.0) which permits unrestricted use, distribution, and reproduction in any medium for non-commercial use provided the original author and source are credited.

\section{INTRODUCTION}

Iatrogenic paralysis of the external popliteal sciatic nerve is a complication that must be taken into consideration in the aftermath of internal opening valgus osteotomy. This lesion may be caused by the guide pin that pierces the external popliteal sciatic nerve. We report a case of paralysis of the popliteal nerve following an internal opening valgus osteotomy that required palliative tendon transfer treatment.

\section{PATIENT AND OBSERVATION}

Mrs. O. L., 49 years old, with no notable pathological antecedent, admitted in our training for the management of right gonalgia evolving since 3 years, clinically it is a virgin right knee of any surgery without frontal or sagittal laxity. The preoperative radiological check-up included a face schuss incidence (Figure-1), a $30^{\circ}$ flexion profile and a pangonogram with bipodal support on which the HKA angle, the femoral mechanical axis and the tibial mechanical axis were measured. Immediate postoperative radiographs included both frontal and profile incidence. Radiographically, internal femorotibial gonarthrosis was classified as Ahlback stage II: femorotibial interline pinch $>50 \%$. The varum is $3^{\circ}$.

By classical internal route, insertion of a guide pin under scopic control, the osteotomy is performed with a pneumatic saw and scissors, the patient had $3^{\circ}$ of varus, the correction will be $8^{\circ}$. Osteosynthesis of the osteotomy with an ISO plate in an inverted L shape with screws on both sides, with partial filling by interposition of a bone substitute wedge. Closure on redon drain.

The postoperative follow-up was simple, patient was discharged at day 2 with posterior atella, anticoagulant and analgesic treatment.

The medium-term follow-up was marked by a paralysis made of steppage with an equinus foot and deficit of the extension of the toes, without anesthesia of the territory of the anterior tibial nerve.

Several EMGs were performed, showing a continuous nerve with very severe involvement of the deep peroneal and a very long recovery.

This prompted admission to the operating room for neurolysis of the external popliteal sciatic nerve, which was performed through an incision facing the head of the fibula, dissection of the external popliteal sciatic nerve, discovery of a para-nervous soft tumor (Figure-2), excision and sending the specimen to histology (Figure-3). Moreover, the nerve is continuous and shows no macroscopic lesions. An anatomopathological analysis showed a postoperative neuroma. 
The patient benefited from resuscitation of the right ankle by tendon transfer from the posterior tibial to restore active dorsal ankle flexion and correct the foot drop deformity. Rehabilitation completed the treatment and the result was satisfactory at 1 year, with complete disappearance of the steppage allowing correct walking. The removal of the plate was performed at 1 year and a half.

Surgical treatment of unicompartmental internal gonarthrosis of the varus knee is based on a tibial valgus osteotomy, the principle of which is widely accepted since, whatever the technique used, it regularly leads to an improvement in the functional symptomatology $[1,2]$. The internal opening osteotomy advocated by several authors [3, 4] is characterized by its simplicity and safety compared to curviplane osteotomies [5]. It has the advantage of avoiding neurological complications of the external popliteal sciatic nerve and the fibular osteotomies required in external subtraction osteotomies. It has the advantage of restoring tension to the internal ligamentous system [6, 7]. It does not jeopardize a subsequent total knee arthroplasty because the metaphyseal bone stock is preserved.

The surgical technique begins with a soft tissue procedure. The patient has given their informed consent for the case to be published.

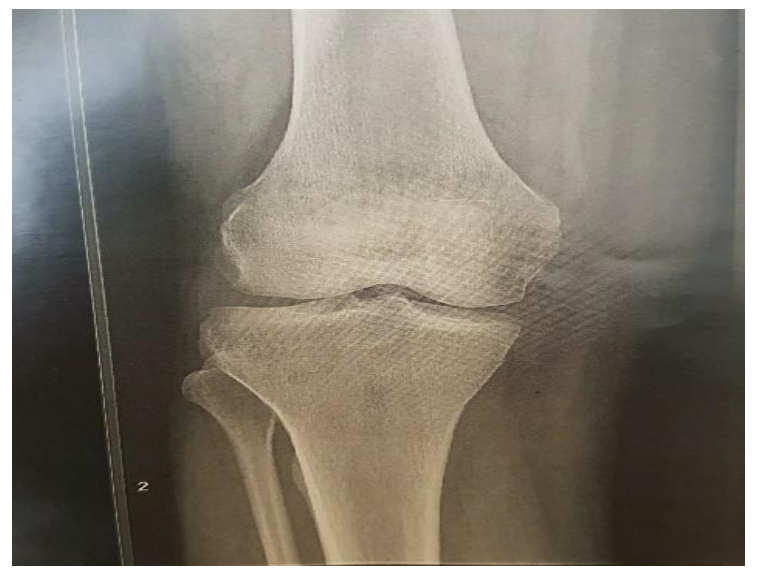

Fig-1: X-ray of the right knee

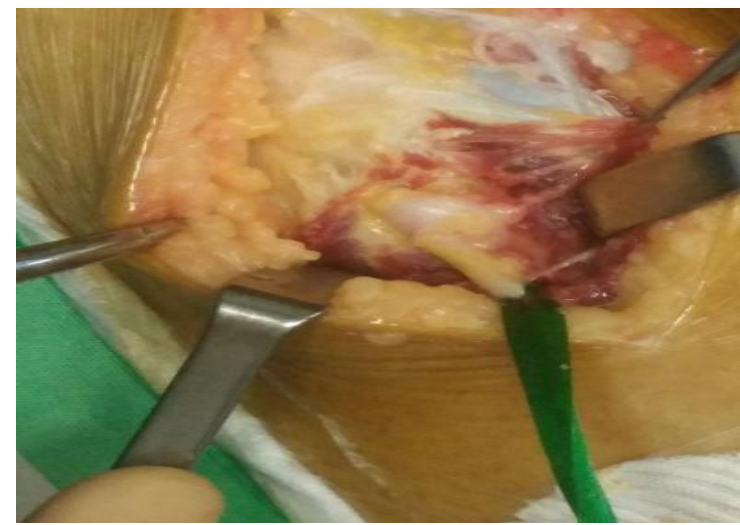

Fig-2: Intraoperative image of the para-nervous tumor

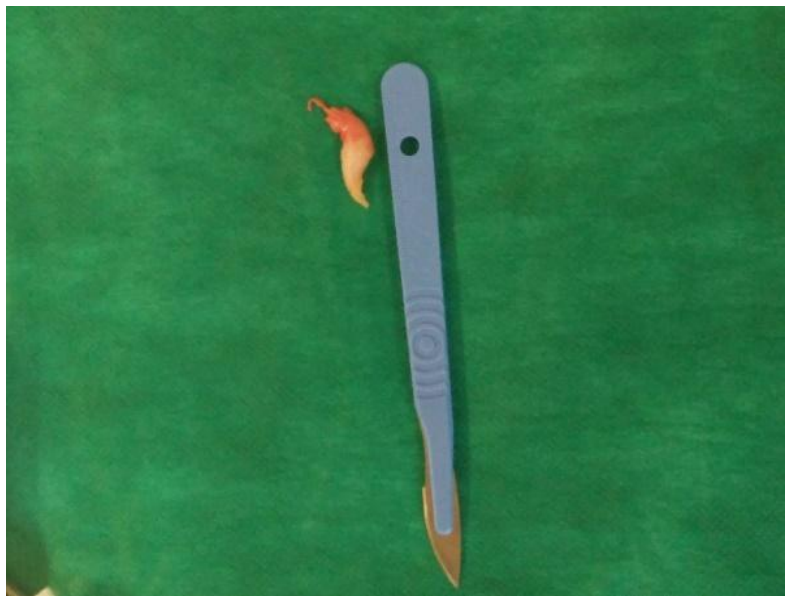

Fig-3: Removal of the neuroma

\section{DISCUSSION}

The osteotomy is performed at the internal cortical concavity of the tibial metaphysis, with the guide wire directed under image intensifier to the upper end of the fibula. The direction of the osteotomy pin depends on the size of the opening to be made. If it is a small opening, the pin may be directed towards the upper end of the head of the fibula. If it is a large opening, it is preferable to direct the pin towards the peroneal-tibial joint. The disadvantage, of course, is that the osteotomy ends in the peroneotibial joint or induces a lesion of the external popliteal sciatic nerve [8].

Once the opening has been made in the manner of a soft postage stamp, the wedge must be placed posterior to the tibial opening. Osteosynthesis by means of a screwed plate is performed. Various filling components are used in practice, but none has proven its superiority [9].

Paralysis of the external popliteal sciatic nerve is frequent, especially for major corrections, but its frequency depends on the technique used, so its occurrence during open VWT is exceptional: 1 case out of 93 for Hernigou [8], this paralysis is due to a lesion of the external popliteal sciatic nerve, probably by the guide wire. Clinically, it manifests itself as a foot drop, resulting in steppage when walking. The extensors of the toes are also deficient. Sensory disturbances are inconstantly absent in our patient.

The electrophysiological examination (EMG) has no indication before the third week post-traumatic or post-surgical, the clinical examination remains the best examination. The EMG makes it possible to separate the neurapraxia from other lesions (axonotmesis and neuromesis) of varying severity. This examination does not make it possible to distinguish between axonotmesis (favourable lesion) and neuromesis (unfavourable lesion). 
This distinction can only be made after a period of evolution or by surgical exploration [10].

As far as neurological management is concerned, Baron [11] advocates conservative medical treatment: functional re-education and the use of an orthosis in case of severe steppage. Infiltrations are also proposed. According to Uzenot et al., [12], surgery is discussed if there are no signs of recovery after six months. Dallary et al., [13], on the other hand, recommend early surgical management as soon as the diagnosis is positive and whatever the etiology, in order to obtain a rapid and complete recovery. According to Ismael et al., [14], the shorter the time before surgery, the more satisfactory the functional recovery.

For our patient, the intervention was performed after 6 months of functional treatment, the failure of neurolysis and the non-improvement and recovery of paralysis, at 1 year, motivated a palliative treatment by tendon transfer from the posterior leg to resuscitate the ankle joint.

\section{CONCLUSION}

The tibial valgus osteotomy by internal addition still holds an important place in the surgical arsenal against gonarthrosis, compared to the different valgus techniques and prosthetic surgery. It is an extraarticular procedure, with a biomechanical basis, which does not carry significant risks and has the power to relieve pain, all while reacting early on the knee varum to slow the progression of osteoarthritis.

However, paralysis of the external popliteal sciatic nerve is an exceptional complication and very rarely described in the literature. It should not be negligible and the insertion of a guide pin should remain a very careful procedure to avoid nerve damage.

Competing Interests: The authors declare no competing interest.

Authors' Contributions: All authors have read and agreed to the final version of this manuscript and have equally contributed to its content and to the management of the manuscript.

\section{REFERENCES}

1. Aglietti P, Rinonapoli E, Stringa G, Taviani A. Tibial osteotomy for the varus osteoarthritic knee. Clin Orthop. 1983 Jun;176:239-51.
2. Insall J, Joseph D, Msika C. High tibial osteotomy for varus gonarthrosis. J Bone Joint Surg. 1984;66 $\mathrm{A}(7): 1040-8$.

3. Blanchard JP, Lord G, Marotte JH, Guillamon JL. Les ostéotomies tibiales de valgisation, choix d'une technique et des gestes associés: a propos de 250 cas.

4. Dohin B, Migaud H, Gougeon F, Dukuennoy A. Effect of a valgisation osteotomy with external wedge removal on patellar height and femoropatellar arthritis. Acta Orthop Belg. 1993;59:6975 .

5. Ivery M. Lateral tibial plateau fracture as a postoperative complications of high tibial osteotomy. Orthopedics. 1985;8(8):1009-13.

6. Lavalle F, Pascal-Mousselard H, Rouvillain JL, Riberyre D, Delattre O, Catonne Y. Cale en céramique biphasée et plaque à vis orientables verrouillées dans les valgisations tibiales par addition. Rev Chir Orthop. 2004;90:550-6.

7. Melchior B, Le Couteur P. Comment nous réalisons nos ostéotomies tibiales de valgisation par addition interne. Maîtrise orthopédique. 1998;70(1)

8. Hernigou P. Technique de l'ostéotomie tibiale de valgisation par ouverture interne. Mises au Point en Chirurgie du Genou, 2013, 120-127.

9. Hernigou P. Technique d'ostéotomie tibiale par ouverture interne. Rev Chir Orthop, 1992;78 (suppl 1):99-101.

10. Wavreille G, Clairemidi A, Sauvage A, Arnaout A, Brulard C, Lasnier A. Lésions traumatiques des nerfs périphériques (plexus brachial exclu). EMCAppareil Locomoteur. 2013;8:1-2.

11. Baron D. Prise en charge locale des syndromes canalaires. Rev Rhum, 2007;74:424-33.

12. Uzenot D, Cantiniaux S, Pouget J. Syndromes canalaires entre « hanches » et « pieds ». Rev Rhum, 2007;74:401-8.

13. Dallari D, Pellacani A, Marinelli A, Verni E, Giunti A. Deep peroneal nerve paresis in a runner caused by ganglion at capitulum peronei: case report and review of the literature. Journal of sports medicine and physical fitness. $2004 \mathrm{Dec}$ 1;44(4):436-40.

14. Ismael F, Wahbi S, Lahtaoui A, Yacoubi H, Bellarbi S, Geanah A, Elmanouar M, Kettani F. Compression du nerf fibulaire commun par un kyste synovial. Rev Maroc Chir Orthop Traumatol. 2005;24:37-9. 